\title{
Cirurgias estéticas, discurso médico e saúde
}

\author{
Aesthetic surgery, medical discourse and health
}

Francisco Romão Ferreira ${ }^{1}$

${ }^{1}$ Núcleo de Pesquisa Ciência e Arte como Estratégia para Educação, Ciência e Saúde, Instituto Oswaldo Cruz, Fundação Oswaldo Cruz. Av. Brasil 4365, Manguinhos.

21045-900 Rio de Janeiro RJ.fromao@terra.com.br
Abstract The increase in plastic surgery interventions in Brazil and the growth of the beauty industry, as well as care of the body and corporal enhancement, are part of a broader process of medical and aesthetic preoccupation with health. According to the Brazilian Plastic Surgery Association there has been a substantial increase in the number of plastic surgery procedures in Brazil. Every year, approximately 350,000 aesthetic surgical interventions are performed in the country. Our work investigated the construction of meaning and value, the use of aesthetic parameters in this construction and how those meanings are appropriated and treated by those representatives of the medical profession who work in the body transformation process, namely plastic surgeons. In this respect, an analysis of the pronouncements and discourse posted on the Brazilian Plastic Surgery Association website was conducted, as it is the regulatory body of the field and is responsible for training professionals and supervising the sector. Analysis of the official content of the website page posted on September 26, 2005 was the basis for this research.

Key words Plastic surgery, Aesthetic surgery, Body, Subjectivity, Speech
Resumo O crescimento do número de cirurgias plásticas no Brasil e a expansão da indústria da beleza, dos cuidados com o corpo e da metamorfose corporal fazem parte de um processo mais amplo de medicalização e estetização da saúde. Segundo dados da Associação Brasileira de Cirurgia Plástica, nos últimos anos houve um número substancial de cirurgias plásticas realizadas no Brasil. A cada ano, em média, são realizadas cerca de 350.000 cirurgias estéticas no país. Nosso trabatho investigou a construção de sentidos e valores, a utilização de parâmetros estéticos nessa construção e a forma como tais sentidos são apropriados e tratados pelos representantes do saber médico que atuam nesse processo de transformação dos corpos, os cirurgiões plásticos. Para tal, foi realizada uma análise dos enunciados e dos discursos disponíveis no endereço eletrônico da Sociedade Brasileira de Cirurgia Plástica, que é a instância reguladora do campo e tem o papel de formar profissionais e fiscalizar o setor. A análise foi realizada a partir do conteúdo oficial do site na página exibida em 26/09/2005.

Palavras-chave Cirurgia plástica, Cirurgia estética, Corpo, Subjetividade, Discurso 


\section{Introdução}

Para melhor compreender as diferentes concepções vigentes de saúde e os cuidados que essas concepções impõem à sociedade urbana ocidental, é preciso levar em consideração fatores como a moda, a produção de subjetividade, o narcisismo e o consumo. O crescimento do número de cirurgias plásticas no Brasil e a expansão da indústria da beleza, dos cuidados com o corpo e da metamorfose corporal fazem parte desse processo mais amplo de medicalização e estetização da saúde, no qual um tipo específico de racionalidade médica é levada a novas esferas da vida cotidiana. Ética, estética e Saúde Coletiva se confundem.

Segundo dados da Associação Brasileira de Cirurgia Plástica ${ }^{1}$, nos últimos anos houve um número substancial de cirurgias plásticas (estéticas e reparadoras) realizadas no Brasil. Só em 2001 foram realizadas cerca de 350.000 cirurgias estéticas no país. Em 2004, foram realizadas 616.287 cirurgias plásticas (sendo 365.698 estéticas e 250.598 reparadoras) e, em 2003, haviam sido realizadas 621.342 (sendo 374.271 estéticas e 247.071 reparadoras). A região Sudeste responde por mais de $50 \%$ das cirurgias realizadas. Em 2004, foram realizadas 212.124 cirurgias no estado de São Paulo, 87.930 em Minas Gerais e 76.078 no Rio de Janeiro, totalizando 376.132 cirurgias apenas nesses três estados.

Esses números colocam o Brasil como o segundo mercado em número de cirurgias plásticas no mundo, perdendo apenas para os EUA, onde há cerca de 800.000 procedimentos por ano. Mas é preciso lembrar que os EUA possuem uma população de cerca de 300 milhões de pessoas (com um poder aquisitivo maior que o nosso). No Brasil, a cada três anos são realizadas mais de 1.000.000 de cirurgias estéticas; são números expressivos que demonstram a necessidade de ampliação da discussão e incorporação dessa nova questão no campo da Saúde Coletiva.

Este trabalho faz parte de uma pesquisa iniciada em 2002 e contém trechos da tese de doutorado intitulada Os sentidos do corpo: cirurgias estéticas, discurso médico e saúde pública, defendida na Escola Nacional de Saúde Pública Sergio Arouca em $2006^{2}$. Nosso trabalho investigou a construção de sentidos e valores acerca do corpo, a utilização de parâmetros estéticos nessa construção de sentidos e a forma como tais sentidos são apropriados e tratados por representantes do saber médico que atuam nesse processo de transformação dos corpos, os cirurgiões plásticos. Para tal, foi realizada uma análise dos enunciados e dos discursos disponíveis no site da Sociedade Brasileira de Cirurgia Plástica ${ }^{3}$, que é a instância reguladora do campo $\mathrm{e}^{4}$ tem o papel de dar o aval aos profissionais e às políticas de atuação do setor. Ela, a SBCP, não apenas habilita os profissionais a atuar profissionalmente como também fiscaliza o setor e é a referência principal do público leigo na hora de consultar quaisquer informações acerca das cirurgias, dos profissionais ou locais disponíveis para realização das cirurgias. Ela é a principal fonte de consulta relativa a qualquer assunto que tange às cirurgias plásticas no país, e todas as matérias (comerciais ou não) publicadas na grande imprensa colocam a SBCP como o maior árbitro e ator do campo. A análise foi realizada a partir do conteúdo oficial do site da Sociedade Brasileira de Cirurgia Plástica, tendo como referência a página exibida em $26 / 09 / 2005$. Nossa análise, portanto, se refere ao conteúdo disponível durante o período em que o conteúdo analisado estava em vigor.

\section{A questão do discurso}

O conhecimento ou a produção de conceitos e discursos acerca do corpo pode agir como fator simultaneamente de manutenção de um determinado conjunto de ideias ou, ao contrário, introduzir ideias que levam à transformação. $\mathrm{O}$ discurso se constitui a partir de reformulações, exclusões, transformações ou interditos, pois, assim como as palavras, o discurso não pode circular livremente, sem compromissos. Com Foucault ${ }^{5}$, aprendemos que a interdição é uma das principais características do discurso, não sendo possível dizer tudo, nem falar em qualquer circunstância, nem sobre qualquer coisa, nem de qualquer modo. Para ele, o discurso não é simplesmente aquilo que traduz as lutas ou os sistemas de dominação, mas aquilo por que, pelo que se luta, o poder do qual nós queremos nos apode$\operatorname{rar}^{5}$. O discurso não se limita a ser meio; ele passa a ser um fim, e a partir da relação que se estabelece com ele podemos perceber os mecanismos de controle, coerção e exclusão.

Aprendemos também que no discurso há a separação e a rejeição, que identificam quem pode falar, quem está autorizado, ou quem determina o que pode ser dito, e de que forma pode ser dito. Deste modo, a fala está intrinsecamente ligada àquele que a pronuncia; o que é dito não somente é de sua responsabilidade como também ganha peso, respeitabilidade, de acordo com aquele que fala, com a posição de quem fala, ou da 
instituição que fala através dos sujeitos que a representam. Para Foucault ${ }^{6}$, essa autoridade do discurso tem relação direta com quem toma a palavra. Segundo ele, quem fala? Quem, no conjunto de todos os indivíduos falantes, tem a autoridade de exercer esta espécie de linguagem? [...] A fala médica não pode vir de qualquer um, seu valor, sua eficácia, seus próprios poderes terapêuticos e, de forma geral, sua existência como fala médica não são dissociáveis do personagem estatutariamente definido que tem o direito de articulá-la ${ }^{6}$.

Mas não se trata apenas de definir o que é certo ou errado na fala, quem pode ou não falar; trata-se de definir que tem o domínio da verdade, quem possui o discurso que neutraliza ou ultrapassa todos os outros discursos. Trata-se de uma vontade de verdade que tende a exercer sobre os outros discursos uma espécie de pressão e como que um poder de coerçãa $o^{7}$. E no caso do discurso que iremos tratar, podemos perceber o quanto essa vontade de verdade exclui todos aqueles discursos que não compartilham da mesma matriz cientificista, instrumental, racionalista e mecanicista.

A ordem do discurso faz com que qualquer coisa que venha a ser dita seja pensada, esquadrinhada, modificada e construída de modo a tentar dizer a palavra certa, o argumento certo, a palavra que convém, o discurso que funcione e que não traga problemas, e para isso as estratégias se rearticulam, (re)utilizando conceitos, ideias ou sentidos proferidos no passado, mas que pos- sam se "atualizar" no discurso atual. O discurso é sempre atualizado sem alterar seu "núcleo duro", suas verdades primeiras.

$\mathrm{O}$ autor do discurso, como sujeito autorizado a falar, desenvolve sua argumentação, a fim de que ela soe como indiscutível, já que se apoia simultaneamente na "mudança" e na tradição. Esse autor, que possui a capacidade técnica e científica que lhe dá o monopólio da autoridade no campo, tem condições de impor aos outros participantes do campo as regras e a forma de acesso não só às regras como também à possibilidade da fala, pois ninguém entrará na ordem do discurso se não satisfizer a certas exigências ou se não for, de início, qualificado para fazê- $-l^{8}$. Ou seja, nem todos os participantes têm acesso ao discurso e muito menos ao poder de proferir discursos, nem todas as regiões do discurso estão disponíveis, nem todas as informações estão acessíveis, e apenas alguns eleitos possuem a chave do cofre.

\section{A SBCP}

No caso do site da SBCP, a tentativa de delimitar o território é explícita; ela aparece em vários momentos. Na fala a seguir (Quadro 1), podemos observar como se dá essa relação e como a instituição cria para si um espaço político, uma hierarquia dentro do campo, de maneira a definir papéis e autorizar (ou não) quem possui o direito à fala:

Quadro 1. Delimitando o território.

A imagem da Cirurgia Plástica é hoje muito boa, devido à qualidade dos cirurgiões brasileiros que se apresentam com excelente formação em um dos serviços credenciados pela SBCP. Entretanto, não se pode ignorar o fato de que existem em atividade pessoas com formação profissional fora dos padrões recomendados pela nossa sociedade, e que vêm divulgando na mídia serviços e técnicas em desacordo com aquilo que se ensina e se divulga nos eventos científicos da SOCIEDADE BRASILEIRA DE CIRURGIA PLÁSTICA, único órgão autorizado a emitir o Título de Especialista em Cirurgia Plástica, através de convênio com a ASSOCIAÇÃO MÉDICA BRASILEIRA e CONSELHO FEDERAL DE MEDICINA.

A nossa entidade tem procurado nos últimos anos, oferecer subsídios à população, no sentido de identificar, através de telefone e internet, dados sobre a filiação ou não de seu médico de escolha. Procuramos destacar também a trajetória do cirurgião membro da SBCP, com destaque para os anos necessários para sua formação, dentro dos quadros da nossa sociedade, além da necessidade de ser membro da mesma, para que possa frequentar os cursos, jornadas e congressos por ela patrocinados.
Somente os profissionais credenciados pela SBCP possuem a qualificação exigida para atuar no campo. Ela não apenas qualifica os profissionais como também delimita quem pode falar, quando e como. Somente seus afiliados possuem $o$ "discurso verdadeiro". 
É preciso passar pelo ritual de qualificação, se submeter às regras do jogo para poder participar. Segundo Foucault, o ritual define a qualificação que devem possuir os indivíduos que falam; define os gestos, os comportamentos, as circunstâncias, $e$ todo o conjunto de signos que devem acompanhar o discurso; fixa, enfim, a eficácia suposta ou imposta das palavras, seu efeito sobre aqueles aos quais se dirigem, os limites do seu valor de coerção9.

A SBCP, que possui o monopólio do discurso, cria então seu "selo de garantia" que atesta a competência científica, a habilidade técnica, a capacidade de decidir, julgar e agir de acordo com o que ela considera correto e "verdadeiro". Somente os profissionais que participam da sua doutrina estão habilitados a proferir discursos verdadeiros; eles possuem a autoridade e o reconhecimento do campo. Através de seus enunciados, podemos observar as estratégias que podem reforçar (voluntariamente ou não) os processos de legitimação, adequando a identidade psicossocial do sujeito à sua posição no campo (e ao uso correto do poder relativo à sua posição), de credibilidade, em que o Dizer e o Fazer se ajustam, ressaltando a competência do locutor (principalmente no que diz respeito ao domínio e à adequação da linguagem), e finalmente as estratégias de captação, que visam seduzir ou persuadir o interlocutor (Quadro 2).

É a partir dessa autoridade que se criam normas acerca do que se fala, de quem possui a competência para falar; criam-se as regras de exclusão e os mecanismos de rejeição quando um sujeito foge às regras estabelecidas, ou seja, a doutrina liga os indivíduos a certos tipos de enunciação e lhes proíbe, conseqüentemente, todos os outros; mas ela se serve, em contrapartida, de certos tipos de enunciação para ligar indivíduos entre si e diferenciá-los, por isso mesmo, de todos os outros ${ }^{10}$. Criase assim uma apropriação social dos discursos na qual os indivíduos que falam estão habilitados a ter acesso a qualquer tipo de discurso, a proferir discursos, a se apropriar deles e desfrutar dos poderes que eles trazem consigo. Da mesma forma, através da doutrina, o discurso segue seu curso a partir e apesar dos sujeitos que o reproduzem; ele ganha vida própria, ele se transforma em uma verdade que se cristaliza e reverbera em domínios que escapam ao primeiro olhar, independentemente dos sujeitos, mas através deles.

O discurso científico de um agente participante de um determinado campo não resulta apenas de um desejo de produção, divulgação ou "atualização" de um saber. Esse discurso necessariamente se articula em torno dos conflitos, das tensões e da dinâmica existente no interior do meio científico no qual ele está inserido. Com Bourdieu $^{11}$, aprendemos também que o campo científico é o lugar de uma concorrência violenta onde o que está em jogo é o monopólio da autoridade científica, o poder de definir, falar e agir legitimamente, de determinar quem possui a capacidade técnica ou a competência científica para opinar, decidir e determinar legitimamente, ou seja, quem pode mandar no campo de maneira autorizada e com autoridade.

Para Bourdieu ${ }^{12}$, o poder simbólico é um poder que atua na construção da realidade, tendendo a estabelecer uma ordem gnoseológica própria, atuando na integração social e na reprodução da ordem social. Segundo ele, é enquanto instrumentos estruturados e estruturantes

Quadro 2. O selo de garantia.

A Sociedade Brasileira de Cirurgia Plástica (SBCP) é uma das maiores associações mundiais da especialidade. Fundada em 1948, é o órgão oficial da Associação Médica Brasileira e Conselho Federal de Medicina a conferir o Título de Especialista em Cirurgia Plástica.

A missão da SBCP é incentivar o avanço na qualidade dos atendimentos oferecidos aos pacientes, através da promoção de altos padrões de treinamento, ética, exercício profissional e pesquisa científica em Cirurgia Plástica. Além da formação e educação continuada oferecida aos seus membros, a SBCP busca uma integração com a comunidade através de comunicações na mídia, site da internet e telefone de contato, visando proporcionar educação pública no que se refere aos assuntos da especialidade.

Apenas os membros da SBCP podem utilizar esta logomarca que expressa um símbolo de excelência em Cirurgia Plástica que você deverá procurar quando for escolher o seu cirurgião.

Legitimação
Credibilidade
Captação


de comunicação e de conhecimento que os sistemas simbólicos cumprem a sua função política de instrumentos de imposição ou de legitimação da dominação ${ }^{12}$. Não há neutralidade possível, na medida em que as tensões do campo revelam os conflitos ideológicos que garantem a hegemonia, a estratificação e a hierarquização do campo, tornando legítima a ordem estabelecida, a dissimulação, as contradições e a demarcação de posições. Desta forma, o que faz o poder das palavras e das palavras de ordem poder de manter a ordem ou de a submeter é a crença na legitimidade das palavras e daquele que as pronuncia, crença cuja produção não é da competência das palavras ${ }^{13}$.

Esse discurso, que é estruturado ao mesmo tempo que estrutura, realiza um trabalho de dissimulação e transfiguração da realidade, fazendo com que seu efeito ideológico se disperse, aparecendo como natural, criando sistemas de classificação e estruturas mentais ajustadas às estruturas sociais, totalmente imersas e mimetizadas sob a aparência de relações de sentido absolutamente banais, normais e corriqueiras ${ }^{14}$.

Nas entrelinhas dos enunciados contidos no site, podemos perceber a elaboração de um discurso ao mesmo tempo estruturado por uma racionalidade médica específica e estruturador da realidade, construindo sentidos, valores, modos de ver, pensar, sentir e agir. Esse discurso reflete todo o conjunto de tensões ideológicas presentes no campo e se revela como um microcosmo da luta simbólica entre os profissionais que atuam no processo, anteriormente descrito, de estetização da saúde. Através do discurso contido no site, podemos identificar as estratégias que, segundo Bourdieu $^{14}$, não correspondem nem a um programa inconsciente, mecanicamente determinado, nem ao produto de uma intenção racional e consciente, mas que estão em sintonia com os discursos que estruturam o campo, o sujeito e a sociedade, conforme pode ser visto no Quadro 3.

Neste enunciado, extraído do primeiro parágrafo da página de apresentação do Guia informativo da SBCP, podemos perceber como a "autoimagem" é naturalizada como se fosse construída individualmente, independentemente do âmbito social ou da cultura, como se o sujeito tivesse acesso a todas as informações e tivesse consciência de seus atos, independentemente da Ideologia ou do Inconsciente. Desta forma, o que pode significar "estar feliz com a sua autoimagem"? Seria estar adaptado às regras do jogo? Ajustado ao controle disciplinar dos corpos? Apenas reproduzir o comportamento esperado socialmente?

Nessa perspectiva, estar "autoconfiante" ou "mais produtivo no trabalho e nas atividades sociais" é o que importa. O pragmatismo, a funcionalidade e a produtividade são vistos como os valores principais da existência. O "parecer" se torna mais importante que o "ser", ou pior, o "parecer” ocupa o lugar do Ser, a existência se dá apenas em função da imagem. Da mesma forma, "se sentir mais confortáveis e seguras nos relacionamentos em geral" passa a ser consequência direta da imagem que se projeta para si e para o mundo, como se apenas a imagem fosse suficiente para nos dar esse conforto e segurança, como se a cirurgia pudesse proporcionar "uma autoimagem forte e positiva" independentemente dos outros fatores ideológicos ou inconscientes, sem levar em consideração a crueldade do real sugerida por Rosset $^{15}$. E as pessoas que não compartilham desse modelo construído socialmente ou que não estão satisfeitas com algum aspecto de sua aparência teriam menos possibilidade de serem au-

Quadro 3. A questão da autoimagem.

Cada um de nós tem a sua "autoimagem", uma percepção de como nos aparentamos para os outros. As pessoas que estiverem felizes com sua autoimagem terão uma melhor probabilidade de serem autoconfiantes, mais produtivas no trabalho e nas atividades sociais, além de se sentirem mais confortáveis e seguras nos relacionamentos em geral. O contrário é verdadeiro para as pessoas que não estão satisfeitas com algum aspecto de sua aparência.

A Cirurgia Plástica estimula e promove uma autoimagem forte $e$ positiva. Mesmo pequenas alterações exteriores podem levar a grandes transformações no interior das pessoas, permitindo que toda a sua autoconfiança venha à tona.
O sujeito constrói sua identidade e se estrutura a partir da "autoimagem"; é ela que vai determinar sua atuação social, mas ao mesmo tempo ela é estruturada pela ordem social.

A CP promove uma autoimagem forte e positiva, mas se esquece de dizer que é a Ideologia que constrói a necessidade dessa autoimagem. 
toconfiantes, seriam improdutivas no trabalho, inadequadas às atividades sociais e não se sentiriam confortáveis e seguras nos relacionamentos em geral. E a solução mágica apresentada é a cirurgia plástica, que "estimula e promove uma autoimagem forte e segura".

Ao afirmar que "pequenas alterações exteriores podem levar a grandes alterações no interior das pessoas, permitindo que toda a sua autoconfiança venha à tona", há uma visível simplificação do processo de construção da identidade e uma desvalorização do movimento contrário, como se pequenas alterações interiores não pudessem desencadear grandes mudanças exteriores, o que nos parece igualmente razoável. E a cirurgia plástica é apresentada como a solução mágica "que proporciona alterações importantes e permanentes", como se ela bastasse por si, como se os problemas relativos à autoconfiança se resumissem à questão da imagem.

No caso da SBCP, as estratégias discursivas se mesclam e se alternam. Por um lado, tentam persuadir o cliente da qualidade de seu produto ou serviço (estratégia de captação), da seriedade e da competência na execução e da garantia de que ele está diante da pessoa ou instituição que reúne os atributos indispensáveis para atendê-lo (estratégia de credibilidade); por outro, delimitam o espaço ao se colocar como o mais qualificado, pois é quem qualifica os profissionais do campo (estratégia de legitimação), enviando um recado explícito para o público interno, ou seja, os outros profissionais que ainda não fizeram a qualificação.

Além disso, ao se metamorfosear em senso comum para criar uma linguagem mais acessível à clientela (utilizando a linguagem da publicidade ou uma abordagem "educativa"), os enunciados evidenciam o funcionamento da instituição, seu posicionamento ante as outras instituições do campo, os conflitos do campo, a forma como a SBCP vê os(as) clientes potenciais, como os profissionais da SBCP percebem os clientes, os clientes que reclamam, os profissionais que não são filiados à instituição, os sentidos atribuídos ao corpo, à relação corpo-mente, os critérios de apreciação da beleza, o que é considerado socialmente belo, as questões relativas ao inconsciente e aos aspectos subjetivos, emocionais ou culturais envolvidos no processo da cirurgia, ou seja, através dos enunciados contidos no site podemos perceber os vestígios da construção discursiva que orienta e a racionalidade que lhe dá sustentação.

\section{A Ideologia, as formações imaginárias e os limites da linguagem}

Todo discurso é proferido a partir de uma posição, uma situação de fala que permite ou não, autoriza ou não, o sujeito que fala. Neste sentido, todo dizer é ideologicamente marcado; sujeito e discurso se confundem, se fundem e materializam suas opções ideológicas. Não há discurso sem sujeito, fora da língua, do simbólico ou da ideologia ${ }^{16}$.

Os enunciados apresentados no site necessariamente traduzem esse jogo simbólico e político, e a partir deles podemos perceber uma racionalidade científica instrumental se manifestando, uma racionalidade que esquece o sujeito e sua subjetividade e afirma um saber que apresenta o corpo como um objeto a ser manipulado de acordo com as exigências da vida cotidiana, fazendo com que as pessoas que estiverem felizes com sua autoimagem terão uma melhor probabilidade de serem autoconfiantes, mais produtivas no trabalho e nas atividades sociais, ou seja, é tudo muito simples, basta seguir as regras do jogo, se adaptar ao modelo social vigente e manter a felicidade para se tornar mais "produtivo". A Ideologia se faz presente nos mínimos detalhes e reproduz a dimensão maquínica de subjetivação sugerida por Guattari e Rolnik $^{17}$. A subjetividade é assumida e vivida no plano individual sem se dar conta da sua construção, que é cultural e social.

Os enunciados que compõem o discurso exposto no site se constituem de um conjunto de falas aparentemente dispersas, com uma origem indefinida, mas formam um mesmo sistema lógico de valores, compondo uma mesma formação discursiva e reproduzindo um conjunto de tipos normativos de enunciação, formas singulares de organização de conceitos e de elaboração de quadros temáticos e teóricos. Os discursos revelam, assim, as relações de força dentro do campo e remetem às formações imaginárias que os sustentam.

Em diversos momentos, ao simular as perguntas que os pacientes devem fazer na hora da consulta, uma questão que se repete é a de como proceder em relação às críticas, às insatisfações ou à ansiedade característica do momento, e a resposta invariavelmente é "converse com o seu cirurgião, e somente com ele", ou "tire suas dúvidas com o seu cirurgião plástico, e somente com ele, as suas eventuais dúvidas", ou ainda conforme aparece no Quadro 4. 
Quadro 4. A relação da imagem com o mundo exterior.

Lidando com a Depressão Pós-Operatória

Logo depois de uma cirurgia, a maioria dos pacientes experimenta transitoriamente alguma sensação de desânimo ou tristeza.

Buscando a Ajuda Adequada

É essencial que você tenha o apoio físico e emocional de pessoas no período pós-operatório. Por mais independente que alguém possa parecer, vai precisar de algum suporte após uma cirurgia. Lembre-se de que nas primeiras semanas você poderá se sentir deprimida pelo desconforto, inchaços e áreas arroxeadas.

Saiba escolher a companhia adequada que seja realmente um suporte. Procure educadamente declinar da oferta de ajuda de pessoas muito críticas e negativistas, além daquelas que não se sentem à vontade com o aspecto edemaciado ao qual temporariamente você estará submetido.

Lidando com as Críticas

Tenha também em mente que não são incomuns comentários do tipo "eu preferia como você era antes" ou "você não precisava ter feito a cirurgia". Tais comentários podem ter diversas motivações, muitas vezes até inconscientes, mas podem determinar um stress adicional ao seu período de recuperação. As críticas de amigos e familiares devem ser encaradas como algo natural de quem está vendo a situação de fora. Também não espere receber elogios - geralmente as pessoas são mais generosas na crítica do que nos elogios. Tenha sempre em mente que você fez a cirurgia pra você mesmo e não para satisfazer outras preferências. Procure apoio nas pessoas de sua maior afetividade e no seu cirurgião para contornar essas dificuldades. Concentre-se nos seus objetivos e nos motivos que o levaram a procurar a cirurgia plástica.

Os aspectos psicológicos são em geral minimizados, as críticas externas tratadas como algo descabido, sem sentido. A companhia adequada é aquela que reforça a escolha pela cirurgia e nunca alguém que pense, analise, avalie os benefícios reais, os custos, os riscos, enfim, qualquer possibilidade de reflexão deve ser evitada. Como se a cirurgia fosse feita apenas "pra você mesmo", independentemente do mundo externo. Como se não existisse alteridade.
A “imagem” idealizada é tratada como se ela fosse o real, como se o que se passa no fundo da caverna fosse a representação da própria realidade, e qualquer posição contrária é vista como negativismo, como se os pacientes tivessem acesso às suas reais motivações e sempre tivessem a capacidade de avaliar ou falar sobre as suas motivações com desenvoltura, honestidade e compreensão total de todo o processo.

O resgate da "autoestima" é sempre evocado como solução ou motivação para o procedimento cirúrgico, sem levar em consideração as ambiguidades e incoerências de qualquer sujeito. As expectativas são tratadas sempre como algo possível de ser vislumbrado a olho nu, como se "formar uma expectativa realista" fosse algo natural, simples e disponível para qualquer mortal em qualquer circunstância ou em qualquer momento da vida.

As palavras não têm sentido nelas mesmas, elas derivam seus sentidos das formações discursivas em que se inscrevem e sua relação com a ideologia; elas permitem a percepção das regularidades no funcionamento do discurso, a dinâmica do campo, a distribuição de poder de acor- do com cada posição (de acordo com a conjuntura sócio-histórica), determinando o que pode ser dito, o que deve ser dito, por quem pode ser dito e de que forma pode ser dito. As formações discursivas representam, assim, através dos enunciados, toda a sua filiação ideológica, pois os sentidos são sempre decorrentes dessa filiação, não havendo sentido gratuito, fora dessa relação, na medida em que tudo o que dizemos está em relação com outros discursos do campo. E isso não está nas palavras em si, mas na relação que elas estabelecem entre si em função dessa dinâmica; os enunciados revelam então esse jogo entre as relações do campo, suas tensões, sua memória, suas imagens, seus conflitos e sua ideologia, expondo as posições, as articulações e os conflitos do campo.

Ao escolher determinada fala, atribuir a ela um determinado sentido e perceber através dela outros sentidos possíveis, estamos lidando com interpretações que definem posições ideológicas. O sentido é fruto de uma relação entre o sujeito e a história, linguagem e mundo, o simbólico e o "real", sabendo que qualquer tentativa de definir um desses termos já define um mundo de possi- 
bilidades, teorias e conceitos, sendo impossível uma posição neutra, fora de qualquer discussão ideológica. Como dito anteriormente, não há discurso fora da língua, do sujeito, da ideologia, sem relação com o inconsciente e sem referência a uma memória. E tanto no discurso quanto em sua interpretação, todos esses fatores estão articulados.

Sabemos que nem os sujeitos, nem os discursos são transparentes e acessíveis; eles se constituem a partir de processos próprios, atravessados pela linguagem e pela história de acordo com o imaginário de cada um. Ao agir, o sujeito produz sentidos e é atravessado pelos sentidos presentes na história e na língua. Por sua vez, o sujeito não tem consciência de tudo o que diz. Ao ser atravessado pelo imaginário, pela ideologia ou pelo inconsciente, o sujeito só tem acesso à parte do que diz. Existe, assim, um lugar do qual o sujeito fala que não é acessível a ele, uma posição que ele ocupa para poder dizer o que diz, ser sujeito daquilo que diz, e o modo como o sujeito ocupa esse lugar, como ele assume essa posição, indica uma filiação a uma identidade relativa às outras no mesmo campo. Assim, há um esquecimento dessa posição, pois é só quando o sujeito passa para o anonimato que o dizer produz seu efeito; quando ele fala "automaticamente", sua fala se revela impregnada de uma memória de que ele sequer se dá conta, e assim, através do sujeito falam as instituições, as racionalidades médicas, a lógica do mercado ou a sua corporação. As falas dos cirurgiões plásticos que estão disponíveis no site permitem perceber esse jogo múltiplo em que falam ao mesmo tempo os sujeitos, a instituição que eles representam e toda a memória da racionalidade médica ocidental, com toda a sua formação tecnicista e mecanicista que nasce com as ciências modernas.

O enunciado presente da fala do editor dos Anais do XLI Congresso Brasileiro de Cirurgia Plás- tica, Jorge Bins Ely, na página do Editorial do presidente da SBCP-Regional SC, revela a forma como alguns cirurgiões se posicionam diante da atividade (Quadro 5).

Apesar de o referido editor não compreender a cirurgia plástica como uma "máquina de ilusões, oficina de fantasia, armazém da fantasia, fábrica de sonhos", aparentemente não compartilhar com a banalização e a mercantilização desta atividade e tentar construir uma imagem mais digna da profissão, esta fala revela que há uma luta interna entre os cirurgiões plásticos e que, para alguns profissionais do campo, existe uma racionalidade instrumental que precisa ser combatida.

Para alguns profissionais, as percepções dualistas, mecânicas e instrumentais que apresentam o corpo como uma linha de montagem fica evidente, o dualismo que separa corpo e alma fica explícito, a falta de cuidado com as questões subjetivas e os aspectos psicológicos, da mesma forma, são banalizados. O sujeito é reduzido a uma coisa, um objeto a ser moldado na mão desse artesão que possui um "conhecimento técnico superespecializado". Em alguns casos, o corpo é visto como uma máquina que precisa ir a uma oficina para sofrer os reparos necessários, para poder sair da fábrica e ser aceito no mercado.

\section{Fábrica de sonhos}

Os sonhos são "fabricados" e vendidos como fantasias possíveis de serem adquiridas no mercado; o único problema é que alguns pacientes não percebem que se trata apenas de retórica e a confundem com a possibilidade de fabricar seus sonhos na realidade. A publicidade e as revistas especializadas criam uma imagem distorcida das cirurgias, banalizando procedimentos cirúrgicos,

Quadro 5. A cirurgia como "fábrica de sonhos".

Nossa especialidade é tão pujante que muitas vezes confundimos corpo e alma; ela é muito mais que cirurgia, é psiquiatria cirúrgica, cirurgia psiquiátrica, máquina de ilusões, oficina de fantasias, armazém da juventude, FÁBRICA DE SONHOS.

$\mathrm{Na}$ verdade não somos vendilhões de ilusões e fantasias nem juventude e sonhos, somos cirurgiões plásticos, técnicos superespecializados com limitações bem conhecidas, a serviço do ser humano, somos laicos, éticos, enfim, seres humanos.
As palavras máquina, oficina, armazém e/ou fábrica não são gratuitas, são metáforas que revelam um modo estruturado e estruturante de pensamento. 
minimizando riscos, promovendo o imediatismo, coisificando o corpo e prometendo melhorias nem sempre possíveis. Os equívocos relativos às expectativas irreais que são sistematicamente propagadas pela mídia especializada contam com a omissão e o silêncio da categoria, na medida em que ela também é beneficiária do crescimento do mercado.

Essa é uma questão polêmica. Se a cirurgia plástica é uma "fábrica de sonhos", uma "oficina de fantasia" ou um "armazém da juventude", o cirurgião se compromete a entregar ao consumidor o produto adquirido. Afinal, ele é o técnico superespecializado que pode tornar realidade o sonho almejado. Ao vender sonhos, os cirurgiões se comprometem em atingir seus objetivos, e a cirurgia que deveria ser uma atividade "meio" passa a se configurar como uma atividade "fim". E o consumidor, que não possui todas as informações necessárias ao adquirir seu produto ou serviço e é influenciado por uma propaganda fantasiosa, compra o produto acreditando que obterá o resultado desejado.

No campo jurídico, a medicina plástica (incluída a dentária) desenvolve-se sob dois aspectos distintos: reparadora ou simplesmente estética. Na cirurgia eminentemente reparadora, o contrato é comum (apenas de meios). Na cirurgia estética (e por isso voluntária), o contrato é duplo: de meios e de resultados, concomitantemente. Ao aceitar realizar uma cirurgia que pode ser considerada desnecessária, o médico assume o risco pelo resultado. Segundo o Supremo Tribunal de Justiça, No procedimento cirúrgico estético, em que o médico lida com o paciente saudável que apenas deseja melhorar sua aparência física $e$, conseqüentemente, sentir-se psiquicamente melhor, estabelece-se uma obrigação de resultado que impõe ao profissional da medicina, em casos de insucesso da cirurgia plástica, presunção de culpa, competindo-lhe ilidi-la com a inversão do ônus da prova, de modo a livrá-lo da responsabilidade contratual pelos danos causados ao paciente em razão do ato cirúrgico ${ }^{18}$.

Mas o que queremos salientar é que essa fala que promete atender à "máquina de ilusões" ou a "oficina de sonhos" não é uma fala qualquer, de um leigo ou de um jornalista em uma revista de divulgação científica ou de apelo popular. Tratase do editor dos anais dos últimos Congressos Brasileiros de Cirurgia Plástica, na página que apresenta os trabalhos científicos da entidade. Não se trata de uma fala desinteressada, neutra, sem responsabilidade ou autoridade no campo; ao contrário, trata-se de uma das falas mais qualifi- cadas no setor, a de quem escolhe, organiza e divulga os trabalhos científicos de toda a categoria.

\section{Os silêncios da Ideologia}

A ideologia opera por inversão, isto é, coloca o efeito no lugar das causas e transforma estas últimas em efeitos, fabricando ideias e falsas causalidades. Ela opera também através do imaginário social, recolhendo imagens diretas e imediatas da experiência social, transformando-as num conjunto coerente, lógico e sistemático que vai instituir normas, regras de conduta e comportamento. Ela produz um tecido de imagens que explicam toda a realidade e prescrevem como a sociedade deve pensar, sentir e agir.

Os sentidos atribuídos ao corpo passam necessariamente por esse filtro ideológico e se apresentam para o senso comum como um conjunto de verdades avalizadas pela ciência que, por sua vez, também cria um discurso próprio aos seus interesses. Uma terceira forma pela qual a ideologia opera é através do silêncio, pois nem tudo pode ser dito, porque, se tudo fosse dito, a fala perderia coerência, se tornaria contraditória e perderia seu crédito. A ideologia oculta suas verdadeiras intenções e se deixa revelar naquilo que lhe convém, fazendo com que os discursos se direcionem para um dos sentidos possíveis, evidenciando alguns, ocultando outros, operando por metáforas para “ocultar a dor”. A coerência e a unidade do discurso estão em relação direta com o que é silenciado, e esses discursos estão na base da constituição dos sujeitos; são esses silêncios que definem a posição e a situação do sujeito no mundo.

Um silêncio esclarecedor observável nos textos dos anais da SBCP se refere à ausência de artigos acerca dos aspectos subjetivos que acompanham as cirurgias plásticas. Entre centenas de artigos disponíveis no site, não foram encontrados artigos que tratassem de questões psicológicas, inconscientes, culturais ou sociais relativas às cirurgias plásticas. Foram buscadas numerosas palavras-chave que pudessem apontar para tais assuntos presentes nos títulos dos artigos e nada foi encontrado nos anos de 2001, 2002, 2003, 2004 e 2005. As palavras-chave utilizadas para busca foram: sujeito, subjetividade, aspectos emocionais, aspectos subjetivos, aspectos psicológicos, aspectos comportamentais, aspectos culturais, comportamento, cultura, inconsciente, consciência, imagem, consumo, narcisismo, idealização, idealização da imagem, imagem idealizada, autoima- 
gem, autoestima, expectativas, ansiedade, expectativas irreais, expectativas fantasiosas, fantasia, idealização, projeção, ideal do Eu, Eu ideal, falsas expectativas, fatores sociais, padrão cultural, cultura, beleza, belo, natural, cultural, social, identidade, singularidade, construção da identidade, padrão de beleza, critérios de beleza, padrão estético, imagem social, pessoa, autoafirmação etc. Não foram encontrados trabalhos em cujos títulos constassem tais palavras-chave.

A ausência de pesquisas nessa área e o silêncio da categoria acerca dessas questões revelam o grau de importância que é dado a elas. O silêncio acerca dos aspectos subjetivos envolvidos nas cirurgias expõe o tipo de racionalidade que está presente, a perspectiva adotada acerca do corpo, do sujeito, dos aspectos psicológicos envolvidos, a reflexão dos profissionais acerca dessas questões e a maneira como tais profissionais produzem sentidos e reproduzem valores acerca do corpo, da beleza, da identidade ou do papel da imagem na nossa sociedade. É um silêncio eloquente.

Diante desse quadro, algumas questões se apresentam, entre elas:

Como pensar a beleza ou a imagem do corpo sem levar em consideração as condições em que esses padrões são criados?

Como interferir no corpo sem levar em consideração os aspectos psicológicos?

Como pensar as cirurgias plásticas nesse contexto de mercantilização da medicina?

Como pensar as cirurgias plásticas sem cair em juízos de valor?

Existe uma reflexão crítica acerca de sua própria atuação?

Como tratar dessas questões de forma isenta e eticamente responsável?

Qual é o papel dos profissionais de saúde diante deste quadro?

Qual o papel dos cirurgiões plásticos nesse processo?

\section{Referências}

1. Peixoto P. Associação Brasileira de Cirurgia Plástica. Pesquisa Gallup Organization. Folha de S.Paulo 2005; 15 nov. (Caderno Cotidiano C3).

2. Ferreira FR. Os sentidos do corpo: cirurgias estéticas, discurso médico e Saúde Pública. [tese]. Rio de Janeiro: Escola Nacional de Saúde Pública Sergio Arouca, Fundação Oswaldo Cruz; 2006.

3. Sociedade Brasileira de Cirurgia Plástica. [site da Internet]. [acessado 2011 fev 28]. Disponível em: www.cirurgiaplastica.org.br

4. Bourdieu P. O poder simbólico. Rio de Janeiro: Bertrand Brasil; 1989.

5. Foucault M. A ordem do discurso. São Paulo: Loyola; 2005. p. 10.

6. Foucault M. A ordem do discurso. São Paulo: Loyola; 2005. p. 68.

7. Foucault M. A ordem do discurso. São Paulo: Loyola; 2005. p. 18.

8. Foucault M. A ordem do discurso. São Paulo: Loyola; 2005. p. 36.

9. Foucault M. A ordem do discurso. São Paulo: Loyola; 2005. p. 39.

10. Foucault M. A ordem do discurso. São Paulo: Loyola; 2005. p. 43.

11. Bourdieu P. Os usos sociais da ciência: por uma sociologia clínica do campo científico. São Paulo: Unesp; 2004.

12. Bourdieu P. O poder simbólico. Rio de Janeiro: Bertrand Brasil; 1989. p. 11.
13. Bourdieu P. O poder simbólico. Rio de Janeiro: Bertrand Brasil; 1989. p. 15.

14. Bourdieu P. O poder simbólico. Rio de Janeiro: Bertrand Brasil; 1989.

15. Rosset C. O princípio de crueldade. Rio de Janeiro: Rocco; 2002.

16. Orlandi EP. Análise do discurso: princípios e procedimentos. Campinas: Pontes; 2003.

17. Guattari F, Rolnik S. Micropolítica: cartografias do desejo. Petrópolis: Vozes; 1999.

18. Sebastião J. Responsabilidade médica: civil, criminal e ética: comentários, referências ao direito positivo aplicável, à doutrina e à jurisprudência. $3^{\mathrm{a}}$ ed., revista e atualizada. Belo Horizonte: Del Rey; 2003. (R.n.81.101-PR, Rel. Ministro Waldemar Zveiter. RT 767, p. 1-125).

Artigo apresentado em 13/02/2008

Aprovado em 19/01/2009

Versão final apresentada em 05/02/2009 